\title{
Fertility-sparing uterine lesion resection for young women with gestational trophoblastic neoplasias: single institution experience
}

\author{
Xiaoyu Wang ${ }^{1}$, Junjun Yang ${ }^{1}$, Jie Li ${ }^{1}$, Jun Zhao${ }^{1}$, Tong Ren ${ }^{1}$, Fengzhi Feng ${ }^{1}$, Xirun \\ Wan $^{1}$ and Yang Xiang ${ }^{1}$ \\ ${ }^{1}$ Department of Obstetrics and Gynecology, Peking Union Medical College Hospital, Chinese Academy of Medical Sciences \\ and Peking Union Medical College, Beijing, PR China
}

Correspondence to: Yang Xiang, email: xiangy@pumch.cn

Keywords: gestational trophoblastic neoplasias; fertility-sparing surgery; uterine lesion resection; prognostic factor; pregnant outcomes

Received: November 02, $2016 \quad$ Accepted: January 09, $2017 \quad$ Published: January 18, 2017

Copyright: Wang et al. This is an open-access article distributed under the terms of the Creative Commons Attribution License 3.0 (CC BY 3.0), which permits unrestricted use, distribution, and reproduction in any medium, provided the original author and source are credited.

\section{ABSTRACT}

Purpose: To evaluate the oncological safety and pregnant outcomes of fertilitysparing uterine lesion resection in treating gestational trophoblastic neoplasias.

Results: After the treatment of surgery and chemotherapy, all the patients achieved complete remission. With a median follow-up time of $\mathbf{4 4}$ months (range, 6-188), 3 patients $(3.85 \%)$ relapsed within 3-26 months. Multivariate analysis showed that tumor size was the independent risk factor of recurrence and the cutoff value was $4.2 \mathrm{~cm}$. Among 37 patients who attempted to conceive, 31 achieved clinical pregnancy. The rate of pregnancy and live birth were $83.8 \%$ and $77.4 \%$. Uterine rupture did not occurred no matter in cesarean section or vaginal delivery. No congenital abnormalities were reported among the live births.

Methods: From January 1995 to December 2014, 78 patients with gestational trophoblastic neoplasias who underwent fertility-sparing uterine lesion resection at Peking Union Medical College Hospital were reviewed. The complete remission rate, fertility rate, pregnant outcomes and risk factors of recurrence were analyzed.

Conclusions: Fertility-sparing uterine lesion resection might be considered as a safe and reasonable alternative for high-selected young women to remove uterine lesion in the treatment of gestational trophoblastic neoplasias.

\section{INTRODUCTION}

Gestational trophoblastic neoplasias (GTNs) used to describe a spectrum of diseases derived from trophoblasts and often occurred in young women of child-bearing age. GTNs are highly responsive to chemotherapy especially in choriocarcinomas even with distant metastasis. Although surgery was considered as a less important approach in the management of GTNs, selected surgical procedures may be necessary for removing chemo-resistant or persistent lesions in uterus and metastatic sites, and for curing severe complications [1]. Hysterectomy is recommended when lesion is localized in uterus, but loss of fertility is the major concern for young women. Previous studies have indicated that the fertility-sparing uterine lesion resection for GTNs is well tolerant, which provides an alternative to eliminate lesion and preserve the fertility function $[2,3]$. However, uterine lesion resection may increase the chance of tumor spread and recurrence so the oncological safety must be balanced. There are several cases of successful pregnancy and delivery after this surgery; in the same time, the risk of uterine rupture is also controversial [4]. The purposes of our study were to analyze the clinical characteristics and oncological safety, as well as the prognosis and reproductive outcomes of patients with GTNs undergoing fertility-sparing uterine lesion resection in Peking Union Medical Collage Hospital (PUMCH) within the past 20 years. 
Table 1: Clinical features of the 78 patient before treatments in our hospital.

\begin{tabular}{|c|c|}
\hline Characteristics & NO. (Ratio) or Mean (Range) \\
\hline Age & $26.5(16-38)$ \\
\hline Gravidity & $2.0(1-6)$ \\
\hline \multicolumn{2}{|l|}{ Parity time } \\
\hline 0 & $63(80.8 \%)$ \\
\hline 1 & $12(15.4 \%)$ \\
\hline 2 & $3(3.8 \%)$ \\
\hline Pretreatment $\beta$-HCG (IU/L) & $154873.2(15.5-3508811)$ \\
\hline \multicolumn{2}{|l|}{ FIGO score } \\
\hline$\leq 6$ & $43(55.1 \%)$ \\
\hline$\geq 7$ & $35(44.9 \%)$ \\
\hline \multicolumn{2}{|l|}{ FIGO stage } \\
\hline $\mathrm{I}$ & $42(53.9 \%)$ \\
\hline II & $1(1.3 \%)$ \\
\hline III & $31(39.7 \%)$ \\
\hline IV & $4(5.1 \%)$ \\
\hline \multicolumn{2}{|l|}{ Metastasis } \\
\hline Lung & $34(43.6 \%)$ \\
\hline Liver & $2(2.6 \%)$ \\
\hline Brain & $1(1.3 \%)$ \\
\hline Vagina & $1(1.3 \%)$ \\
\hline Pelvic wall & $1(1.3 \%)$ \\
\hline \multicolumn{2}{|l|}{\begin{tabular}{|l} 
Previous GTN history \\
\end{tabular}} \\
\hline $\mathrm{NO}$ & $70(89.7 \%)$ \\
\hline YES & $8(10.3 \%)$ \\
\hline \multicolumn{2}{|l|}{ Resistant to multi-drug chemotherapy } \\
\hline $\mathrm{NO}$ & $68(87.2 \%)$ \\
\hline YES & $10(12.8 \%)$ \\
\hline
\end{tabular}

\section{RESULTS}

\section{Patient characteristics}

The demographic characteristics of enrolled 78 patients before treatment in our hospital were displayed in Table 1. With the mean age of 26.5 years (range, 1638 years), 63 patients $(80.8 \%)$ were nulliparae. The mean serum $\beta$-hCG level before treatment was 154873.2 (range, 15.5-3508811) IU/L. 43 patients (55.1\%) were low-risk according to the International Federation of Gynecology and Obstetrics (FIGO) prognostic scoring system. 42 patients were diagnosed with stage I, 1 with stage II, 31 with stage III, and 4 with stage IV. The percentage of patients with metastases was $46.2 \%$ (36/78), which included 34 cases with lung metastases, 2 with liver metastases, 1 with vaginal metastasis, 1 with brain metastasis and 1 with pelvic wall metastasis. 8 patients had GTN history before and 10 patients were transferred to our hospital because resistant to multi-drug chemotherapy in local hospitals.

\section{Treatments}

The median course of chemotherapy before surgery was 3.5 (range, $0-12$ ). The mean preoperative serum $\beta$-hCG level was 4778.3 (range, $0-213857$ ) IU/L. The indications for surgery were persistent lesion, chemoresistant lesion, unclear diagnosis and suspected uterine rupture, in 51 patients $(65.4 \%), 13$ patients $(16.7 \%), 9$ patients $(11.5 \%)$ and 5 patients $(6.4 \%)$, respectively. The mean preoperative serum $\beta$-hCG level in above was 0.7 (range, 0-4.4) IU/L, 123.8 (range, 5.8-1294) IU/L, 494.9 (range, 15.8-3071.3) IU/L, and 73321.2 (range, 14160-213857) IU/L, respectively. The mean size of lesion in the uterus was 3.7 (range, $3.0-8.1$ ) $\mathrm{cm}$. The median postoperative chemotherapy course was 3 (range, 0-6). Combined medical history, previous and present histological and immunohistochemical results, the 78 patients were diagnosed as the following: 26 invasive moles, 40 choriocarcinomas and 12 placental site trophoblastic tumors (PSTTs). These included 3 invasive moles and 2 choriocarcinomas in 5 patients with uterine rupture, and 8 PSTTs and 1 choriocarcinoma in 9 patients with unclear diagnosis before surgery. Detailed treatment information was showed in Table 2. 
Table 2: Clinical features of the 78 patient within treatments.

\begin{tabular}{|l|c|}
\hline \multicolumn{1}{|c|}{ Characteristics } & NO. (Ratio) or Mean (Range) \\
\hline Surgical indications & $51(65.4 \%)$ \\
\hline Persistent lesion & $13(16.7 \%)$ \\
\hline Chemo-resistant lesion & $9(11.5 \%)$ \\
\hline Unclear diagnosis & $5(6.4 \%)$ \\
\hline Suspected uterine rupture & $3.5(0-12)$ \\
\hline Median preoperative chemotherapy course & $4778.3(0-213857)$ \\
\hline Preoperative serum $\beta$-HCG (IU/L) & $0.7(0-4.4)$ \\
\hline Persistent lesions & $123.8(5.8-1294)$ \\
\hline Chemo-resistant lesions & $494.9(15.8-3071.3)$ \\
\hline Unclear diagnosis & $73321.2(14160-213857)$ \\
\hline Suspected uterine rupture & $3.7(3.0-8.1)$ \\
\hline Uterine lesion size in the surgery $(\mathrm{cm})$ & $2372.2(0-126321)$ \\
\hline Postoperative serum $\beta$-HCG (IU/L) & $0.3(0-2.9)$ \\
\hline Persistent lesions & $47.5(0.2-567)$ \\
\hline Chemo-resistant lesions & $76.8(2.3-456)$ \\
\hline Unclear diagnosis & $36741.2(5100-126321)$ \\
\hline Suspected uterine rupture & $3(0-6)$ \\
\hline Median postoperative chemotherapy course & \\
\hline
\end{tabular}

Table 3a: Clinical characteristics of the 3 patients relapsed after treatments.

\begin{tabular}{|c|c|c|c|c|c|c|c|c|c|c|c|c|}
\hline No & Age & Gravidity & Parity & $\begin{array}{l}\text { GTN } \\
\text { type }\end{array}$ & $\begin{array}{l}\text { FIGO } \\
\text { stage }\end{array}$ & $\begin{array}{l}\text { FIGO } \\
\text { score }\end{array}$ & Metastasis & $\begin{array}{l}\text { Pretreatment } \\
\beta-H C G\end{array}$ & \begin{tabular}{|l|} 
Previous \\
GTN \\
history \\
\end{tabular} & \begin{tabular}{|l|}
$\begin{array}{l}\text { Resistant } \\
\text { to multi- } \\
\text { drug }\end{array}$ \\
\end{tabular} & $\begin{array}{l}\text { Surgical } \\
\text { indication }\end{array}$ & \begin{tabular}{|l|}
$\begin{array}{l}\text { Preoperative } \\
\text { chemotherapy } \\
(\text { regimen* } n .)\end{array}$ \\
\end{tabular} \\
\hline 1 & 23 & 1 & 0 & $\mathrm{CC}$ & IV & 11 & Lung, liver & 981100 & NO & YES & $\begin{array}{l}\text { Chemo-resistant } \\
\text { lesion }\end{array}$ & $\begin{array}{l}\text { Other hospital } * 2 \\
(5 F U+\text { Act }-D * 2) \\
\text { FAEV } 2 \\
\text { EMA/CO } 4\end{array}$ \\
\hline 2 & 38 & 5 & 0 & $\mathrm{CC}$ & I & 11 & $\mathrm{NO}$ & 2383 & YES & NO & $\begin{array}{l}\text { Chemo-resistant } \\
\text { lesion }\end{array}$ & $\begin{array}{l}\text { FAEV*4 } \\
\text { EMA/CO*3 }\end{array}$ \\
\hline 3 & 27 & 4 & 0 & $\mathrm{CC}$ & I & 8 & NO & 60000 & $\mathrm{NO}$ & YES & Persistent lesion & $\begin{array}{l}\text { Other hospital } * 5 \\
(P E B * 3, \\
E M A / C O * 2) \\
E M A / C O * 3\end{array}$ \\
\hline
\end{tabular}

Abbreviations: CC, choriocarcinoma; 5FU, 5fluorouracil; Act-D,dactinomycin; EMA/CO, etoposide + methotrexa te+dactinomycin/cyclophosphamide+vincristine; FAEV, floxuridine+dactinomycin+vincristine+etoposide; PEB, cisplatin+etoposide+bleomycin.

Table 3b: Clinical characteristics of the 3 patients relapsed after treatment.

\begin{tabular}{|c|c|c|c|c|c|c|c|c|c|}
\hline No & $\begin{array}{l}\text { Preoperative } \\
\beta \text {-HCG (IU/L) }\end{array}$ & $\begin{array}{l}\text { Surgical } \\
\text { mode }\end{array}$ & $\begin{array}{l}\text { Tumor } \\
\text { size } \\
(\mathrm{cm})\end{array}$ & $\begin{array}{l}\text { Postoperative } \\
\beta-H C G \\
\text { (IU/L) }\end{array}$ & $\begin{array}{l}\text { Postoperative } \\
\text { chemotherapy } \\
\text { (regimen*n.) }\end{array}$ & \begin{tabular}{|l|} 
Time to \\
recurrence \\
(months)
\end{tabular} & Recurrent site & $\begin{array}{l}\text { Recurrent } \\
\text { treatment }\end{array}$ & $\begin{array}{l}\text { Status } \\
\text { (months) }\end{array}$ \\
\hline 1 & 120 & Laparotomy & 3.3 & 21 & $\mathrm{EMA} / \mathrm{CO} * 5$ & 6 & Uterus, brain, lung & Chemotherapy & DOD (16) \\
\hline 2 & 10.5 & Laparotomy & 5.6 & 0.6 & $\mathrm{EMA} / \mathrm{CO}^{*} 3$ & 3 & Uterus, lung & $\begin{array}{l}\text { Chemotherapy, } \\
\text { pulmonary } \\
\text { lobectomy }\end{array}$ & $\begin{array}{l}\text { NED } \\
(7)\end{array}$ \\
\hline 3 & 1.6 & Laparotomy & 5.2 & 0 & $\mathrm{EMA} / \mathrm{CO}^{*} 3$ & $3,12,26$ & Uterus, lung & $\begin{array}{l}\text { Chemotherapy, } \\
\text { hysterectomy }\end{array}$ & NED (45) \\
\hline
\end{tabular}

Abbreviations: DOD, dead of disease; NED, no evidence of disease.

\section{Follow-ups}

After the completion of treatment, all patients achieved complete remission (CR). The median follow-up time was 44 months (range, 6-188). Three of 78 patients relapsed after CR within 3-26 months, one of which had three times of recurrence; the recurrent rate was $3.85 \%$. Table $3 \mathrm{a}$ and Table $3 \mathrm{~b}$ showed the clinical characteristics of 3 patients who relapsed after the completion of treatment. They received chemotherapy with or without surgery when relapsed and one of them died due to tumor progression.

In the follow-up time, 41 patients selected continuous contraception because of young age, having child before, or for fear of recurrence. In the other 37 patients, 31 were successful pregnant $(83.8 \%)$. There were 22 term deliveries $(71.0 \%), 2$ preterm deliveries, 1 uterine scar pregnancy, 1 cornual pregnancy, 1 
Table 4: Results of the univariate analysis for recurrence (qualitative indicators).

\begin{tabular}{|c|c|c|c|c|}
\hline & $\begin{array}{c}\text { Totality } \\
(n, \%)\end{array}$ & $\begin{array}{c}\text { No recurrence } \\
(n, \%)\end{array}$ & $\begin{array}{c}\text { Recurrrence } \\
(n, \%)\end{array}$ & $P$ value \\
\hline Total number & 78 & $75(96.2 \%)$ & $3(3.8 \%)$ & \\
\hline \multicolumn{5}{|c|}{ Resistant to multi-drug chemotherapy } \\
\hline NO & $68(87.2 \%)$ & $67(98.5 \%)$ & $1(1.5 \%)$ & \multirow{2}{*}{0.04} \\
\hline YES & $10(12.8 \%)$ & $8(80 \%)$ & $2(20 \%)$ & \\
\hline \multicolumn{5}{|l|}{ Previous GTN history } \\
\hline NO & $70(89.7 \%)$ & $68(97.1 \%)$ & $2(2.9 \%)$ & \multirow{2}{*}{0.28} \\
\hline YES & $8(10.3 \%)$ & $7(87.5 \%)$ & $1(12.5 \%)$ & \\
\hline \multicolumn{5}{|l|}{ Surgical indications } \\
\hline Persistent lesion & 51 & $50(98.1 \%)$ & $1(1.9 \%)$ & \multirow{2}{*}{0.10} \\
\hline Chemo-resistant lesion & 13 & $11(84.6 \%)$ & $2(15.4 \%)$ & \\
\hline Unclear diagnosis & 9 & $9(100 \%)$ & 0 & \multirow{2}{*}{$\mathrm{N} / \mathrm{A}$} \\
\hline Suspected uterine rupture & 5 & $5(100 \%)$ & 0 & \\
\hline \multicolumn{5}{|l|}{ FIGO stage } \\
\hline I & 42 & $40(92.9 \%)$ & $2(7.1 \%)$ & \multirow{4}{*}{ N/A } \\
\hline II & 1 & $1(100 \%)$ & 0 & \\
\hline III & 31 & $31(100 \%)$ & 0 & \\
\hline IV & 4 & $3(80 \%)$ & $1(20 \%)$ & \\
\hline \multicolumn{5}{|l|}{ Surgical mode } \\
\hline Laparotomy & $56(71.8 \%)$ & $53(94.6 \%)$ & $3(5.4 \%)$ & \multirow{2}{*}{0.56} \\
\hline Laparoscopy & $22(28.2 \%)$ & $22(100 \%)$ & 0 & \\
\hline
\end{tabular}

Abbreviations: N/A, not applicable.

spontaneous abortion, 1 mid-term induced abortion due to fetus cleft lip, 1 repeated hydatidiform mole, and 2 ongoing pregnancies in their first pregnancies. No congenital abnormalities were reported among the live births. Among the 24 term and preterm deliveries, the cesarean section accounted for $83.3 \%(20 / 24)$ and uterine rupture not occurred no matter in cesarean section or vaginal delivery.

\section{Statistical analysis}

In univariate analysis, resistant to multi-drug chemotherapy, FIGO score and tumor size were significantly associated with recurrence, which were shown in Table 4 and Table 5. A multivariate analysis of aforementioned factors identified the tumor size (OR $=6.184,95 \% \mathrm{CI}: 1.090-35.071, P=0.040)$ was an independent risk factor for recurrence. Different tumor sizes were used to calculate the sensitivity, specificity and Youden's index, and these results revealed that the maximal Youden's value correlated with a tumor diameter of $4.2 \mathrm{~cm}$ (Sensitivity 1.0, Specificity 0.8 , Youden's index 0.8 ). It means that patients with tumor diameter of $4.2 \mathrm{~cm}$ or above have more possibilities of recurrence after uterine lesion resection surgery.

\section{DISCUSSION}

With the development of sensitive assays of $\beta$-hCG, the effective chemotherapy regimens and the recognition of risk factors, the cure rate of GTNs could almost reach $100 \%$ in low-risk patients even with metastasis and $94 \%$ in high-risk patients [5]. However, it is important to remove the chemo-resistant or persistent lesions through surgery in order to cure disease and reduce the chance of relapse. With an incidence ranging from $5.2 \%$ to $23.4 \%$, many centers had reported their experience of hysterectomy in the management of uterine lesion [1, 6-8]. Fertility-sparing uterine lesion resection, which combined conservative myometrium resection with uterine reconstruction, can be considered in highly-selected patients who desire for preserving future fertility. However, compared to the vast reports about hysterectomy in management of GTNs, there was a paucity of publication describing fertilitysparing surgery, especially regarding rare types. Therefore, retrospective analysis of prognosis and pregnancy outcomes may contribute to establish better therapeutic strategies for young patients with GTNs, particularly when it comes to the fertility-sparing surgery.

Once definitely diagnosed for GTN, chemotherapy is the primary approach, both in low-risk and high-risk 
Table 5: Results of the univariate analysis for recurrence (quantitative indicators).

\begin{tabular}{|c|c|c|c|c|c|c|c|c|}
\hline & Category & Case & Mean \pm SD & Median & InterQuartile range & Minimum-maximum & $\mathbf{Z}$ & $P$ \\
\hline \multirow{2}{*}{ Age } & 1 & 75 & $26.43 \pm 4.71$ & 26.00 & 7.00 & $16.00-42.00$ & \multirow{2}{*}{-0.639} & \multirow{2}{*}{0.553} \\
\hline & 2 & 3 & $29.33 \pm 7.68$ & 27.00 & 15.00 & $23.00-38.00$ & & \\
\hline \multirow{2}{*}{ FIGO score } & 1 & 75 & $5.79 \pm 2.815$ & 6.00 & 4.00 & $1.00-12.00$ & \multirow{2}{*}{-2.313} & \multirow{2}{*}{0.015} \\
\hline & 2 & 3 & $10 \pm 1.732$ & 11.00 & 3.00 & $8.00-11.00$ & & \\
\hline \multirow{2}{*}{ Tumor size } & 1 & 75 & $3.62 \pm 0.74$ & 3.30 & 1.00 & $3.00-5.60$ & \multirow{2}{*}{-2.556} & \multirow{2}{*}{0.005} \\
\hline & 2 & 3 & $5.87 \pm 1.99$ & 5.20 & 3.80 & $4.80-8.10$ & & \\
\hline
\end{tabular}

Abbreviations:1, group of not recurrence after treatments; 2, group of recurrence after treatments.

patients. However, rapid growth and massive hemorrhage of tumors may result in a surgical emergency. Uterine perforation due to myometrium invasion is one of these emergent conditions. Uterine arterial embolization (UAE) is a safe and effective treatment for terminating vaginal excessive bleeding. The purposes of fertilitysparing emergent surgery were to stop bleeding, establish diagnosis and remove lesions as possible. Patients should be well informed about surgical risk and intraoperative frozen pathology was necessary. No severe intraoperative and postoperative complication was occurred in our study. The pathologic results were 3 invasive moles and 2 choriocarcinomas. All the 5 patients received powerful chemotherapy after surgery and achieved complete remission. In the follow-up times, none of them relapsed and 2 had successful pregnancies (the other 3 patients were in contraception). Therefore, as for uterine rupture with invasive mole or choriocarcinoma, uterine lesion resection combined with subsequent chemotherapy may be a feasible and safe therapeutic strategy.

Sometimes it is difficult to distinguish incomplete abortion, cornual pregnancy, interstitial tubal pregnancy, and cesarean scar pregnancy from GTNs, especially with a low serum $\beta$-hCG level. The symptoms of amenorrhea, vaginal bleeding, pelvic pain and the imaging features of uterine mass with abundant blood flow are similar to some extent. Timely diagnosis could avoid progression of disease and shorten treatment time. Curettage may provide histologic evidence but sometimes it is difficult to obtain tissues. Suzuki [9] reported hysteroscopy could not only confirm complete evacuation of hydatidiform mole but also contribute to the diagnosis and management of invasive mole and choriocarcinoma. As to lesions away from uterine cavity, laparotomic or laparoscopic exploration may provide a better strategy in the diagnosis and differentiation, and treatment of GTNs. In our series, chemotherapy was administered after pathological examination and CR was obtained in all 9 patients.

PSTT is a rare type of gestational trophoblastic neoplasias, derived from intermediate cytotrophoblasts, accounted for $0.5-3 \%$ of all type of GTNs according to population-based study $[10,11]$. Surgery plays an important role in the treatment of PSTT because it was not sensitive to chemotherapy. Hysterectomy is widely accepted as the primary treatment for PSTT confined to the uterus. Shen [12] and Zhao [10] had summarized a series of PSTT cases which received fertility-sparing therapy, included diagnostic curettage, resection of lesion by hysteroscopy, and laparoscopic or laparotomic uterine lesion resection. The age older than 35 years may be a risk factor for prognosis [12]. Although there were not enough literatures about uterine lesion resection with PSTT $[10,12-15]$, the prognosis and fertility outcomes were encouraging. However, as to patients with large tumor size, multiple metastases or finished childbearing, uterine lesion resection was not recommended. In our series, there were 12 patients receiving this surgery, including 9 with stage I and 3 with stage III. All the 12 patients were younger than 35 years, untreated cases and had no GTN history. 1 patient only received surgery and the other 11 accepted postoperative chemotherapies. In the follow-up time, none of the 12 patients relapsed and 5 of them had term deliveries.

Our data showed that the recurrent rate of patients receiving uterine tumor resection was $3.85 \%$, which was similar to all GTNs reported in other literatures (4\%$8 \%)[16,17]$. Univariate analysis showed that resistant to multi-drug chemotherapy, FIGO score and tumor size were significantly associated with recurrence. And the result of multivariate analysis implied the tumor size was the independent risk factor. Higher FIGO score and chemo-resistance were the risk factors reported in many literatures $[8,18,19]$. Even though surgery could improve the prognosis especially for patients with chemo-resistant and recurrent GTNs [20], uterine lesion resection need to be paid more attention. Due to lack of big sample about lesion resection surgery in other centers, the suitable tumor size for surgery is not definite. Large lesion especially with unclear border may increase the risk of tumor residues. Although the result of our study showed that the tumor size was the independent risk factor of recurrence and the cutoff value was $4.2 \mathrm{~cm}$, it should be noted that, the $95 \%$ of confidence interval in multivariate analysis was relative broad due to only 3 cases relapsed in our series. Larger sample was needed to confirm this finding.

Spontaneous abortion and adverse maternal outcomes tended to occur in patients conceived within 6 months after chemotherapy completion [21], and untimely pregnancy after surgery may increase the risk of uterine rupture, so patients are advised for contraception at last 12 months after completion of treatment in our center. Some of patients may express worries about future pregnancies, 
particularly the recurrence of GTNs, adverse pregnancy outcomes and fetal malformations [22], which are the same concerns of doctors before clinical decisions. With a theoretical risk of ovarian dysfunction, resumption of normal menstruation appears in almost $95 \%$ of women treated with chemotherapy for GTNs [23]. In our series, except 2 patients were amenorrhea after chemotherapy, the other 76 patients $(97.4 \%)$ resumed menstruation within 2 to 6 months. A review article summing up the data from 7 international medical centers showed that the rate of term live delivery in women treated with chemotherapy for GTNs was higher than $70 \%$ without increased risk of congenital abnormalities [26]. Woolas [27] summarized the rate of pregnancy was $83 \%$ in patients with GTNs after methotrexate (MTX) or EMA/ CO (etoposide, MTX, dactinomycin/cyclophosphamide, vincristine) chemotherapy. Besides the chemotherapy, uterine surgery also has influence on fertility outcomes, which may have potential risk of scar pregnancy, abortion and uterine rupture. Behtash [3] reported 2 cases with choriocarcinomas were successful pregnant after localized resection of perforated uterus. In our study, 37 patients attempted pregnancy and 31 succeeded $(83.8 \%)$. In the 31 gestations, the rate of live birth and term delivery was $77.4 \%$ and $71.0 \%$ respectively, while the rate of premature deliveries, miscarriage, repeated mole, scar pregnancy and fetal abnormalities were $6.5 \%, 3.2 \%, 3.2 \%, 3.2 \%$ and $3.2 \%$, respectively. Braga [21] reported pregnant outcomes of 252 patients with GTNs receiving chemotherapy alone, and the rate of term deliveries, preterm deliveries were $68.2 \%$ and $4.2 \%$, which were similar to our data; while the rate of spontaneous abortion was $16.7 \%$, which may related to some patients conceiving within 6 months after chemotherapy. Intraoperative suture carefully and layer by layer may decrease the risk of uterine rupture in future pregnancy. Even that elective cesarean section was recognized a better way to ensure maternal and perinatal safety, 4 term infants were delivered vaginally without uterine rupture in our study.

In conclusion, fertility-sparing uterine lesion resection might be considered as a safe and reasonable alternative for highly-selected young women with GTNs including PSTTs; all the patients achieved CR after surgery and chemotherapy in our series. Even in the emergency with uterine perforation, and under the situation of unclear diagnosis, localized resection combined subsequent chemotherapy also could be a safe method to cure disease and preserve fertility. Although our sample was limited, the recurrent rate was only $3.85 \%$ and similar to all GTNs, but more attention should be placed on these with larger tumor size. The rate of fertility and pregnant outcomes were satisfied as chemotherapy alone. Neither uterine rupture nor neonatal abnormality was found in our data. However, long term follow-up and additional samples would be necessary to confirm our findings.

\section{METERIALS AND METHODS}

The retrospective study collected 78 patients with GTNs who underwent fertility-sparing uterine lesion resection from January 1995 to December 2014 in PUMCH. Information was reviewed by collecting medical files and making telephone interviews. This study was approved by the Institutional Review Board of PUMCH.

\section{Preoperative treatments}

Before treatment, all patients received disease evaluations consisting of complete medical history reviews, blood sample tests of serum $\beta$-hCG levels, common blood counts, liver and renal function measures, and distant metastatic organs assessment. Pelvic examinations including ultrasound, CT or MRI were necessary to evaluate uterine lesion. Patients were scored and staged on the basis of the FIGO scoring/staging system 2000. Among the 78 patients, 67 accepted chemotherapy as primary treatment. Different chemotherapy agents were chosen due to tumor diagnosis and FIGO score. As to low-risk patients, single agent chemotherapy such as dactinomycin or MTX was administered. Other patients received multi-drug chemotherapy, regimens containing FAEV (floxuridine, dactinomycin, etoposide, vincristine), FAV (floxuridine, dactinomycin, vincristine) [28, 29], EMA/CO, EMA/EP (etoposide, MTX, dactinomycin/ etoposide, cisplatin). The toxicity of chemotherapy and serum $\beta$-hCG were examined weekly and pelvic ultrasound was evaluated every 2-3 courses. Chemoresistance was diagnosed when serum $\beta$-hCG not decline logarithmically, remained or rose after 2 consecutive chemotherapy courses.

\section{Perioperative treatments}

The indications of uterine lesion resection were suspected uterine rupture, unclear diagnosis, and diameter of chemo-resistant (serum $\beta$-hCG $>5 \mathrm{IU} / \mathrm{L}$ ) or persistent (serum $\beta$-hCG $<5 \mathrm{IU} / \mathrm{L}$ ) lesions larger than $3 \mathrm{~cm}$. Diffuse and more than one lesion in uterus were the contradiction of surgery. Surgical risk was fully informed to patients and their families before operation. Patients who were suspected uterine rupture received UAE before emergent surgery. A total of twenty-two patients (28.2\%) received laparoscopic uterine lesion resection. During the surgery, pelvic and abdominal organs were inspected carefully in order to reconfirm the lesion's location and size. The operative range included the whole lesion and surrounding tissue about $0.5-1 \mathrm{~cm}$ as possible. Uterus was reconstructed after myometrium and seromuscular layer sutured separately. MTX or 5-floxuridine was multiple injected around uterine incision. The intraoperative frozen pathology was examined especially in the emergency of 
uterine perforation and unclear diagnosis before surgery. Chemotherapy was administered in definitely diagnostic patients during perioperative period.

\section{Postoperative treatments}

Except one patient only received surgery, other 77 patients underwent subsequent and consolidation chemotherapy after surgery. The regimens were the same as preoperative. After the completion of treatment, all the patients underwent regularly and long-term followup for serum $\beta$-hCG. Complete remission was obtained when serum $\beta$-hCG decreased to normalization at least 4 consecutive weeks. While relapse was diagnosed as serum $\beta$-hCG increased 3 months after complete remission.

\section{Statistical analysis}

All statistical analyses were performed with the Statistical Package for the Social Science, version 16.0 (SPSS 16.0, Chicago, IL, USA). The frequency distributions were compared by Fisher Exact Test. Wilcoxon Rank Sum Test was applied for quantitative parameters. Logistic regression method was used for the multivariate analysis. $\mathrm{P}$ value less than 0.05 was considered to be statistically significant.

\section{ACKNOWLEDGMENTS}

We are grateful to all the patients who have taken part in this study.

\section{CONFLICTS OF INTEREST}

The authors report no conflict of interest.

\section{FUNDING SUPPORT}

This work was supported by grants from the National Natural Science Foundation of China (Grant No. 81672586).

\section{REFERENCES}

1. Eoh KJ, Chung YS, Yim GW, Nam EJ, Kim S, Kim SW and Kim YT. Role of surgical therapy in the management of gestational trophoblastic neoplasia. Obstetrics \& gynecology science. 2015; 58:277-283.

2. Kanazawa K, Sasagawa M, Suzuki T and Takeuchi S. Clinical evaluation of focal excision of myometrial lesion for treatment of invasive hydatidiform mole. Acta Obstet Gynecol Scand. 1988; 67:487-492.

3. Behtash N, Ansari S and Sarvi F. Successful pregnancy after localized resection of perforated uterus in choriocarcinoma and a literature review. International Journal Of Gynecological Cancer. 2006; 16:445-448.

4. Case AM, Wilson S, Colgan TJ and Greenblatt EM. Fertility-sparing surgery, with subsequent pregnancy, in persistent gestational trophoblastic neoplasia: case report. Human reproduction. 2001; 16:360-364.

5. Alifrangis C, Agarwa R, Short D, Fisher RA, Sebire NJ, Harvey R, Savage PM and Seckl MJ. EMA/CO for highrisk gestational trophoblastic neoplasia: good outcomes with induction low-dose etoposide-cisplatin and genetic analysis. J Clin Onco. 2013; 31:280-286.

6. Pisal N, North $\mathrm{C}$, Tidy $\mathrm{J}$ and Hancock B. Role of hysterectomy in management of gestational trophoblastic disease. Gynecologic Oncology. 2002; 87:190-192.

7. Clark RM, Nevadunsky NS, Ghosh S, Goldstein DP and Berkowitz RS. The evolving role of hysterectomy in gestational trophoblastic neoplasia at the New England Trophoblastic Disease Center. J Reprod Med. 2010; 55:194198.

8. Fang J, Wang S, Han X, An R, Wang W and Xue Y. Role of adjuvant hysterectomy in management of high-risk gestational trophoblastic neoplasia. Int J Gynecol Cancer. 2012; 22:509-514.

9. Suzuki A, Kawaguchi K, Konishi I, Ida K, Fujii S and Matsuura S. Role of hysteroscopy in diagnosis and management of trophoblastic disease. Nihon Sanka Fujinka Gakkai zasshi. 1984; 36:255-260.

10. Zhao J, Lv W, Feng F, Wan X, Liu J, Yi X, Qu P, Xue F, Wu Y, Zhao X, Ren T, Yang J, Xie X and Xiang Y. Placental site trophoblastic tumor: A review of 108 cases and their implications for prognosis and treatment. Gynecol Oncol. 2016; 142:102-108.

11. Lybol C, Thomas CM, Bulten J, van Dijck JA, Sweep FC and Massuger LF. Increase in the incidence of gestational trophoblastic disease in The Netherlands. Gynecol Oncol. 2011; 121:334-338.

12. Shen X, Xiang Y, Guo L, Feng F, Wan X, Xiao Y, Zhao $\mathrm{J}$ and Ren T. Fertility-preserving treatment in young patientswith placental site trophoblastic tumors. Int $\mathrm{J}$ Gynecol Cancer. 2012; 22:869-874.

13. Ashton E, Szutowska M, Shafer A and Hoffman J. Attempted conservative management of a placental site trophoblastic tumor: a case report. Connecticut medicine. 2014; 78:475-477.

14. Tsuji Y, Tsubamoto H, Hori M, Ogasawara T and Koyama K. Case of PSTT treated with chemotherapy followed by open uterine tumor resection to preserve fertility. Gynecol Oncol. 2002; 87:303-307.

15. Machtinger R, Gotlieb WH, Korach J, Fridman E, Apter S, Goldenberg $\mathrm{M}$ and Ben-Baruch $\mathrm{G}$. Placental site trophoblastic tumor: outcome of five cases including fertility preserving management. Gynecol Oncol. 2005; 96:56-61.

16. Mutch DG, Soper JT, Babcock CJ, Clarke-Pearson DL and 
Hammond CB. Recurrent gestational trophoblastic disease. Experience of the Southeastern Regional Trophoblastic Disease Center. Cancer. 1990; 66:978-982.

17. Yang J, Xiang Y, Wan X and Yang X. Recurrent gestational trophoblastic tumor: management and risk factors for recurrence. Gynecol Oncol. 2006; 103:587-590.

18. Li J, Shi Y, Wan X, Qian H, Zhou C and Chen X. Epithelioid trophoblastic tumor: a clinicopathological and immunohistochemical study of seven cases. Medical oncology. 2011; 28:294-299.

19. Yang J, Xiang Y, Wan X, Feng F and Ren T. Analysis of the prognosis and related factors for patients with stage IV gestational trophoblastic neoplasia. Int J Gynecol Cancer. 2014; 24:594-599.

20. Doll K and Soper J. The role of surgery in the management of gestational trophoblastic neoplasia. Obstet Gynecol Surv. 2013; 68:533-542.

21. Braga A, Maestá I, Michelin O, Delmanto L, Consonni M, Rudge $\mathrm{M}$ and Belfort P. Maternal and perinatal outcomes of first pregnancy after chemotherapy for gestational trophoblastic neoplasia in Brazilian women. Gynecol Oncol. 2009; 112:568-571.

22. Matsui H, Iitsuka Y, Suzuka K, Yamazawa K, Seki K and Sekiya S. Outcome of subsequent pregnancy after treatment for persistent gestational trophoblastic tumour. Human reproduction. 2002; 17:469-472.

23. Even C, Pautier P, Duvillard P, Floquet A, Kerbrat P, Troalen F, Rey A, Balleyguier C, Tazi Y, Leary A, Augereau P, Morice P, Droz J, et al. Actinomycin D, cisplatin, and etoposide regimen is associated with almost universal cure in patients with high-risk gestational trophoblastic neoplasia. Eur J Cancer. 2014; 50:2082-2089.

24. Bower M, Rustin G, Newland E, Holden L, Short D,
Foskett M and Bagshawe K. Chemotherapy for gestational trophoblastic tumours hastens menopause by 3 years. Eur J Cancer. 1998; 34:1204-1207.

25. Wong JM, Liu D and Lurain JR. Reproductive outcomes after multiagent chemotherapy for high-risk gestational trophoblastic neoplasia. J Reprod Med. 2014; 59:204-208.

26. Gadducci A, Lanfredini $\mathrm{N}$ and Cosio S. Reproductive outcomes after hydatiform mole and gestational trophoblastic neoplasia. Gynecological endocrinology. 2015; 31:673-678.

27. Woolas RP, Bower M, Newlands ES, Seckl M, Short D and Holden L. Influence of chemotherapy for gestational trophoblastic disease on subsequent pregnancy outcome. British journal of obstetrics and gynaecology. 1998; 105:1032-1035.

28. Li J, Yang J, Liu P, Ren T, Zhao J, Feng F, Wan X and Xiang Y. Clinical characteristics and prognosis of 272 postterm choriocarcinoma patients at Peking Union Medical College Hospital: a retrospective cohort study. BMC cancer. 2016; 16:347.

29. Yang J, Xiang Y, Wan X, Feng F and Ren T. Primary treatment of stage IV gestational trophoblastic neoplasia with floxuridine, dactinomycin, etoposide and vincristine (FAEV): A report based on our 10-year clinical experiences. Gynecol Oncol. 2016; 143:68-72. 